\title{
DESIGN AND ANALYSIS OF A DYNAMIC SPLINT BASED ON PULLEY ROTATION FOR POST- STROKE FINGER EXTENSION REHABILITATION DEVICE
}

\author{
Zakki Fuadi Emzain \\ Department of Mechanical Engineering, \\ State Polytechnic of Malang, Indonesia \\ zfemzain@polinema.ac.id \\ Shyh-Chour Huang \\ Department of Mechanical Engineering, \\ National Kaohsiung University of \\ Science and Technology, Taiwan \\ shuang@cc.kuas.edu.tw \\ Yu-Sheng Yang \\ Department of Occupational Therapy, \\ Kaohsiung Medical University, Taiwan \\ ysy205@gmail.com \\ Nanang Qosim \\ Department of Mechanical Engineering \\ State Polytechnic of Malang, Indonesia \\ nanangqsm@polinema.ac.id
}

The presence of rehabilitation tools is essential to more rapidly cure hand muscle disorders of people affected by stroke. One of the tools is a dynamic splint that is fit-sized, lightweight, comfortable to wear, and easy to operate. The paper proposes the design and analysis of new dynamic splints based on pulley rotation as a rehabilitation device for finger extension after stroke. This device consists of the main splint, the pulley, the locker, the finger handles, the ball bearing, and the fishing line. To lock and stop pulley turning, the locking system is designed to complement it which is also the most important mechanical segment. The shear stress of the pulley was $0.026 \mathrm{~N} / \mathrm{mm}^{2}$. The deformation, stress, and strain energy of the locking system section were analyzed by the finite element method. The results showed that the deformation distribution around the locker section was at 0.1-0.15 mm intervals. The maximum stress $25.0786 \mathrm{MPa}$, which is still inferior to the yield strength of ABS Material (28.5 MPa). The safety factor of the structure is about $n=1.14$. The largest strain energy was 0.2856 $m J$ at the same place as with the maximum stress which was close to the conical end of the locker. The correlation between stressstrain energy and moment was linear as well. In future work, a prototype will be fabricated using $3 D$ printers, and it will be applied to the stroke patient. In addition, the therapies will be involved to assess the improvement of the finger extension of stroke patients.

Keywords: Dynamic Splint; Pulley Rotation; Finger Extension; Rehabilitation Device.

\section{INTRODUCTION}

Hands are one of the most important organs of the human body, especially in activities of daily living (ADL) such as reaching, grasping, and lifting objects. However, the hand will not function properly if an accident or a disease like a stroke. Stroke is the third most common cause of death, after coronary heart disease and cancer [1]. In the United States, 795,000 people continue to experience a new or recurrent stroke each year [2]. Meanwhile in Taiwan stroke patients who are registered in the hospital reached 30,599 people between 2006 - 2008 base on the Taiwan Department of Health database [3]. It is the main cause of adult disability with $30 \%$ to $66 \%$ of individuals because one of the effects of a stroke is paralysis in some organs [4]. Organs dysfunction in the upper limb and finger extension are mostly impaired by approximately $75 \%$ [5]. In Taiwan, around $69 \%$ to $80 \%$ of stroke patients have the muscle weakness symptom of the upper limb [6].

The hand impairment causes the hampered of exploring and manipulating a surrounding object functionally. A major source of the impairment is neuromuscular disorders which frequently prevent effective occupational performance. One study in England showed that more than 50\% of stroke patients relied on help others six months post-stroke. However, only $5 \%$ to $20 \%$ of stroke patients can completely recover the upper limb six months after the stroke [7]. If individuals did not be rehabilitated properly then more than $80 \%$ of them affected by hemiparesis after a stroke cannot completely heal the hands and arms back to normal. To solve this problem, it is necessary to use splint as a rehabilitation device. The main purposes of splinting are to improve hand function, increase the range of motion (ROM), reduce spasticity, prevent contracture, motor 
recovery occurs, and influence muscle extensibility in patients [9].

In the last decade, various rehabilitation training devices have been developed to help stroke patients for overcoming hand impairment. Generally, the therapeutic devices are divided into two types: soft glove [10],[11],[12] and robotic hand [13],[14]. For soft glove, there are several kinds of actuators such as pneumatic [15], fiber-reinforced [16], spring [17], or motor [18]. Some researchers also have developed the hand rehabilitation models integrating with virtual display [19],[20],[21],[22]. These robotic devices are promising, with the ability to finely control assistance levels to each digit during task practice [23]. However, these robots are complex, large volume, difficult installation, and staying at clinic therapy [24],[25]. Furthermore, for glove device which requires a virtual reality system or computer graph, are passive devices, and not able to produce assistive external force at the finger [26]. The important one is costly and cannot be affordable by all the patients. In order to be affordable from all people of rehabilitation centers, hospitals, and individuals, it is necessary that the device has a moderate price, which is achieved by using low-cost materials and easy to produce.

The purpose of this study is to design and analyze a new dynamic splint based on pulley rotation as a biomedical rehabilitation device for finger extension after stroke. The main material of this device is ABS material printed out by using the 3D printer. Besides, there are some complement components such as bearing, fishing line, and fastener tape. To complete it, the locking system with several holes was designed to stop the rotation of pulley at a certain stage. Therefore, in this model, the locking system is an important segment to be analyzed when applying the moment. The finite element analysis (FEA) is utilized to find out the deformation, stress, and strain energy distribution of the model. In addition, the device is simple and easy to operate so the device becomes useful and the patient can use it independently without help a caregiver.

\section{MECHANICAL DESIGN}

The dynamic splint for finger extension was designed by using Inventor software with the total dimension $200 \mathrm{~mm} \times 115 \mathrm{~mm} \times 85 \mathrm{~mm}$ in length, width, and height because of the limitation of 3D print size. The main dynamic splint was assembled from 4 parts: the main splint, pulley, locker, and bearing as shown in Figure 1. All of the parts will be printed out using acrylonitrile butadiene styrene (ABS) material because the material is light, inexpensive, and easy to fabricate. Stainless steel small ball bearing is used as a commercial product with a size $9 \mathrm{~mm}$ inner diameter, $20 \mathrm{~mm}$ outer diameter, and $6 \mathrm{~mm}$ thickness. In order to make comfortable with hand, the shape of the main splint was designed like the upper surface of the hand which covers from the forearm, wrist, and dorsal hands. To secure the splint and hold it in place during long-term wear, straps with hook and loop closures are used. To avoid pressure in the inner wrist the soft pad also is attached inside the splint.

While the other parts are finger handle which was designed with an elongated cone shape to suit with a finger as depicted in Figure 2. The shape between thumb and index or middle finger was made a difference because the movement and position are also different. The fingers have 2 movements which are extension and flexion but for the thumb not only that, it also has abduction and adduction. Moreover, the thumb position when extension should rest on the back pedestal of the splint for hyperextension preventing. Thus, the line hook of thumb was placed at the back end of the handle. Whereas the line hook of finger handle was placed in the middle due to keeping the balance of finger when pulling by-line to a maximum extent.

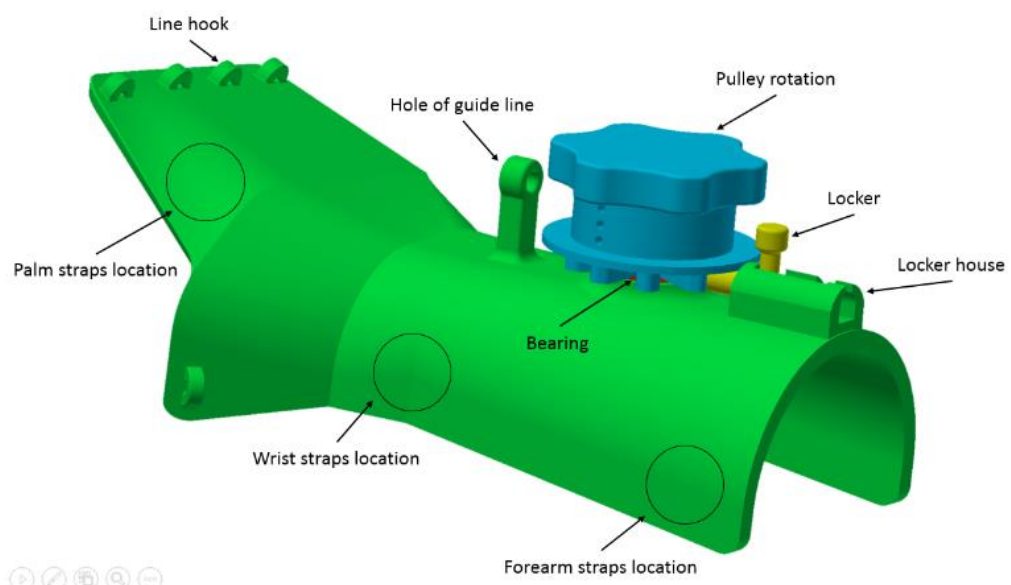

Figure 1: 3D model of the dynamic splint 


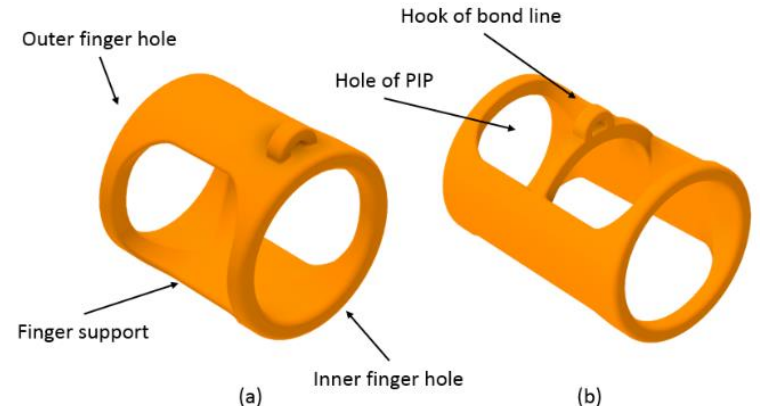

Figure 2: Model of different finger handle: (a) Thumb, (b) Index, and middle finger

The mechanism of the dynamic splint based on pulley rotation is like the fishing principle. At the initial position, the finger of a stroke patient is totally flexion and strongly tied. The next step inserts the finger handle to the thumb, index, and middle while apply the main dynamic splint to hand. After tying all parts then turn the pulley at the clockwise direction and automatically the finger will extension because it is connected to a line. When pulley rotation, the force and moment will accumulate on the pulley axis and bearing. To strengthen the base can be stick with super glue then the locking system was permitted to defense rotation pulley finger pulling. Figure 3 illustrates the mechanism of the locking system which easies to operate. Its function is also very important to keep finger extension which reduces finger flexor hypertonic muscle tone when the subject wearing a prolonged period of time. All the part size depends on the patient hand size except the locking system and pulley which is the same. The dimension of pulley shown in Figure 4.

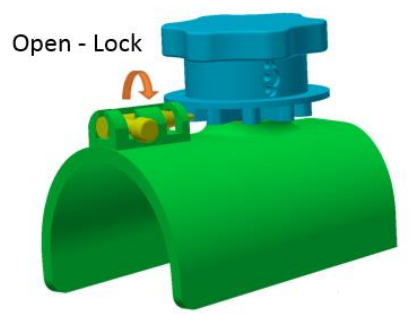

(a)

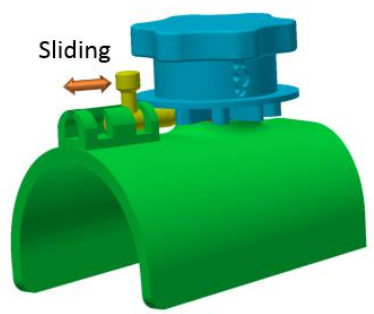

(b)

Figure 3: Locking system mechanism: (a) Open-lock; (b) Sliding

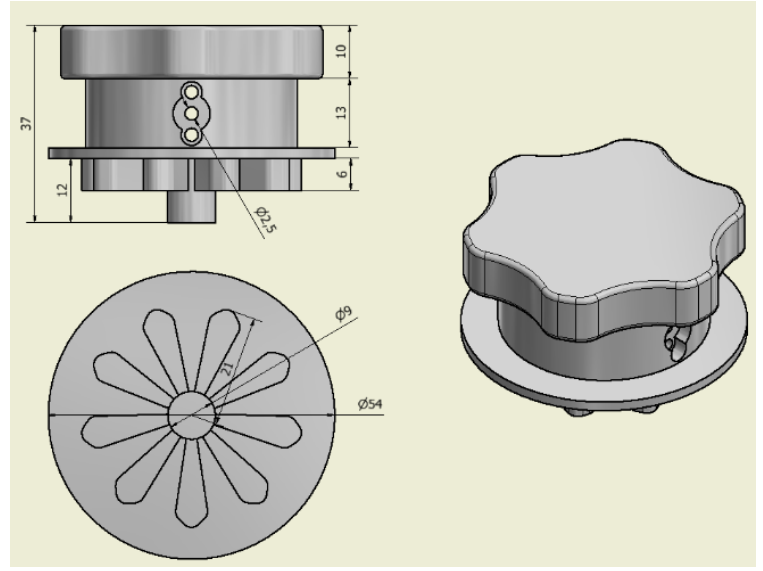

Figure 4: The dimension of the pulley 


\section{DYNAMIC ANALYSIS}

The goal of the dynamic analysis was to calculate the torque on a pulley and shear stress of the pulley. Assuming that at the initial position, the pulley was aligned with the vertical direction and finger force $(F)$ comes from the front of the pulley, as shown in Figure 5 (a). The radius of pulley $R=22 \mathrm{~mm}$ and the pulley mass $M=16.69 \mathrm{~g}$. The finger forces each finger and patient differs depend on their muscle tone by about 5 to $20 \mathrm{~N}$ [27][28]. Then it is assumed to take the maximum force $(F)$ which is $20 \mathrm{~N}$ and resulted in $(T)$ torque at the pulley to the counterclockwise as a positive direction. Because of locking system holes, the pulley would rotate at a certain each angle $\theta=40^{\circ}$ was shown in Figure 5 (b).

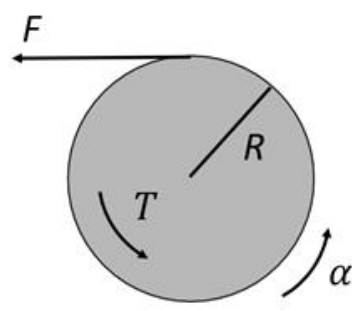

(a)

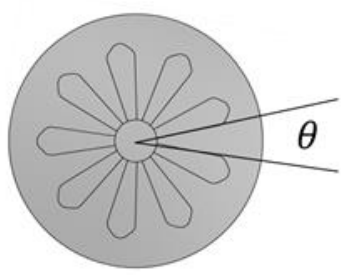

(b)

Figure 5: (a) Pulley rotation at the counterclockwise direction; (b) The angle each hole of the locking system

The torque on the pulley $(T)$ can be calculated by the formula equation 1 as follows:

$T=F R$

The rotational inertia of the pulley $(I)$ of the pulley can be determined by the following equation 2 :

$I=\frac{1}{2} M R^{2}$

The torsional moment area of solid cylinder $(J)$ can be defined by the equation 3 as follows:

$J=\frac{1}{2} \pi R^{4}$

The torsional stiffness of the pulley $(k)$ can be computed by the following equation 4 :

$k=\frac{G J}{L}$

The shear stress in a solid cylinder of pulley $(\tau)$ can be expressed by equation 5 as follows:

$\tau=\frac{T R}{J}$

Where $G$ is Young's modulus of the ABS material which is $2400 \mathrm{MPa}$ [29] and $\alpha$ is the angular acceleration. Because it was assumed that pulley is like a tube with height $(L) 31 \mathrm{~mm}$, so the torsional stiffness $k$ is $2.8 \times 10^{6} \mathrm{Nmm} / \mathrm{rad}$ and the shear stress of pulley is $0.026 \mathrm{~N} / \mathrm{mm}^{2}$.

\section{FINITE ELEMENT ANALYSIS}

The simulation of dynamic splint based on pulley rotation was performed via the finite element analysis (FEA) in ANSYS 18.1 software with the static structural type. The analysis was a focus on the locking system when the device lock position to measure the durability of the model when used by stroke patients. The ABS material was chosen for the main splint part, pulley part, and locker part, while stainless steel ball-bearing was inserted as a lap around with friction ignored. The mechanical properties of ABS material were given in Table 1 [30],[31],[32]. It was inputted to engineering data while stainless steel used available data. At the meshing stage was set manually, for body part which closes to locking contact the element size was $3 \mathrm{~mm}$ whilst the other part was set $5 \mathrm{~mm}$ as shown in Figure 6 (a). For boundary condition, forearm to wrist cover was selected as fixed support and the pulley was given a moment maximum $10 \mathrm{Nm}$ which assumed the strongest muscle tone of a stroke patient with clockwise direction as shown in Figure 6 (b). According to the Skewness scale, the high result of element metrics was in interval range 0.25 to 0.5 . Hence, the quality of the meshed model was very good as shown in Figure 7. 
Table 1: Characteristics of The ABS Material

\begin{tabular}{l|l|l}
\hline CHARACTERISTIC & VALUE & UNIT \\
\hline Density & 1.04 & $\mathrm{~g} / \mathrm{cm} 3$ \\
\hline Young's modulus & 2400 & $\mathrm{MPa}$ \\
\hline Poisson's ratio & 0.37 & \\
\hline Yield strength & 28.5 & $\mathrm{MPa}$ \\
\hline
\end{tabular}

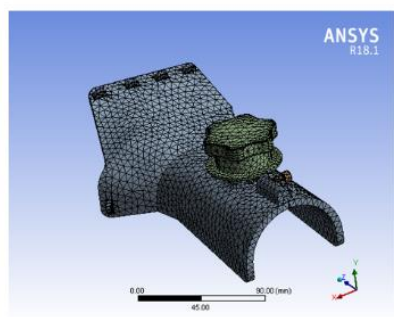

(a)

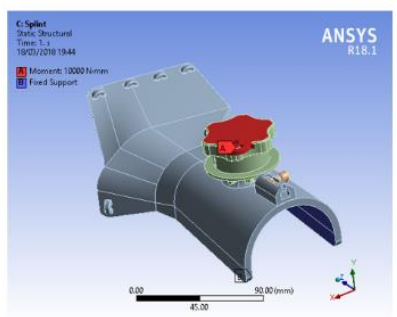

(b)

Figure 6: (a) Meshing model; (b) Boundary condition model

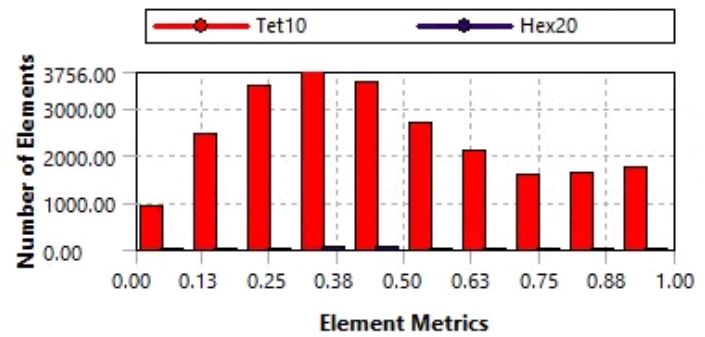

Figure 7: The evaluation results of the meshing quality

\section{RESULTS AND DISCUSSIONS}

The results of deformation showed that the pulley part was the highest of deformation distribution because of a rotation part. The important part is in locker and locker house which slightly bent and based on the color indicator, for locker deflection was approximately 0.1 to $0.15 \mathrm{~mm}$ in range as depicted in Figure 8 (a). The graphic of shape transformation every moment is shown in Figure 9, it was linear. On the other hand, the biggest of von-misses stress result occurred in the locker part particularly in the frontier between tube and cone shape close to the tip. Figure 8 (b) depicts the maximum stress marked on the label which was 25.0786 $\mathrm{MPa}$. The graphic of stress correlation with a moment from $1 \mathrm{Nm}$ to $10 \mathrm{Nm}$ was linear well as shown in Figure 10. To avoid static failure, the maximum stress was still inferior to the strength of the ABS material (28.5 $\mathrm{MPa}$ ). The safety factor ratio was safe approximately $n=1.14$ after calculation.

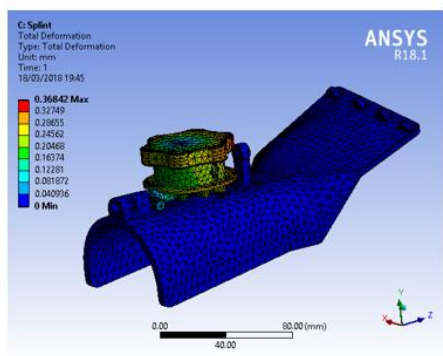

(a)

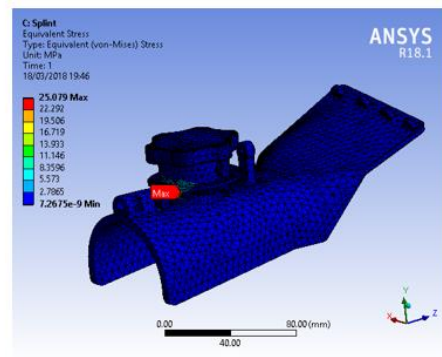

(b)

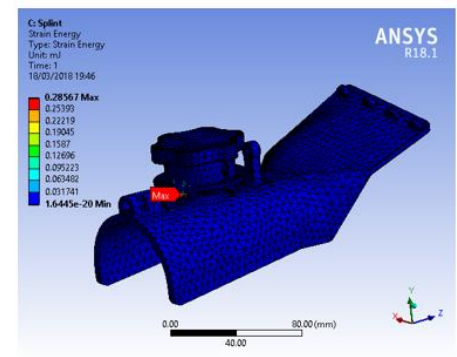

(c)

Figure 8: (a) The result of deformation; (b) The result of von-misses stress; (c) The result of strain energy 


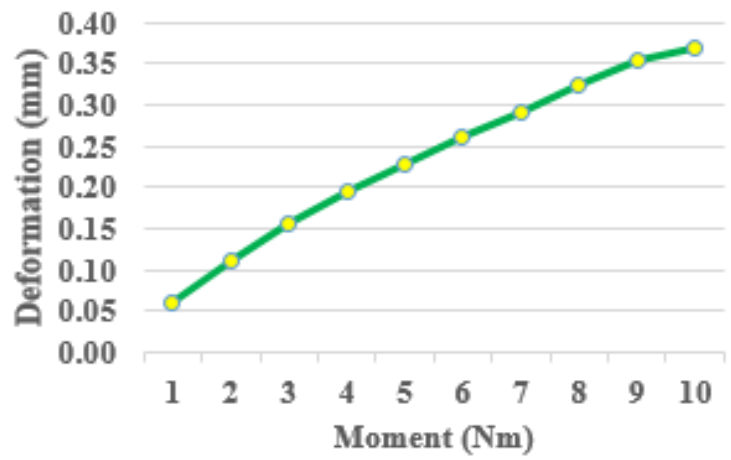

Figure 9: Correlation between the moment and deformation

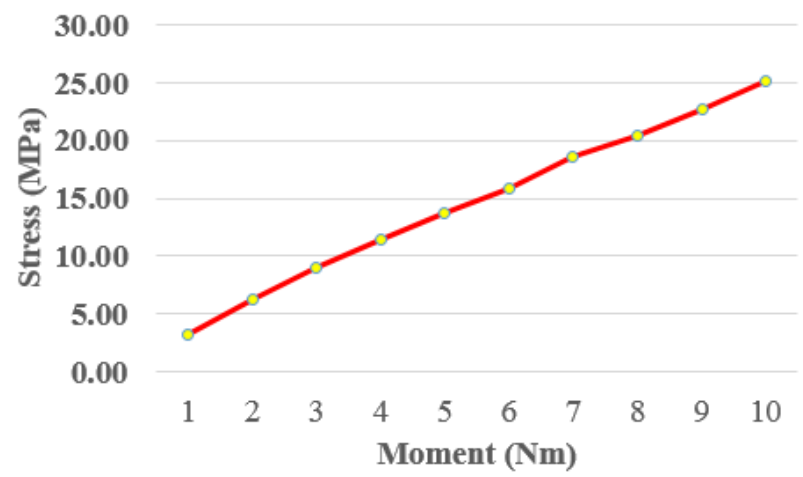

Figure 10: Correlation between moment and von-mises stress

The maximum strain energy appeared at the same location uniformly with the maximum stress corresponding to a maximum moment of $10 \mathrm{Nm}$. These energies concentrated at the border and spread to the nearest area of the locker part. The result of maximum strain energy found about $0.2856 \mathrm{~mJ}$ which marked on the label as shown in Figure 8 (c), it also can support to withstand the torque of pulley. In addition, Figure 11 illustrates the relationship between strain energy and moment of the dynamic splint, it was linear well too.

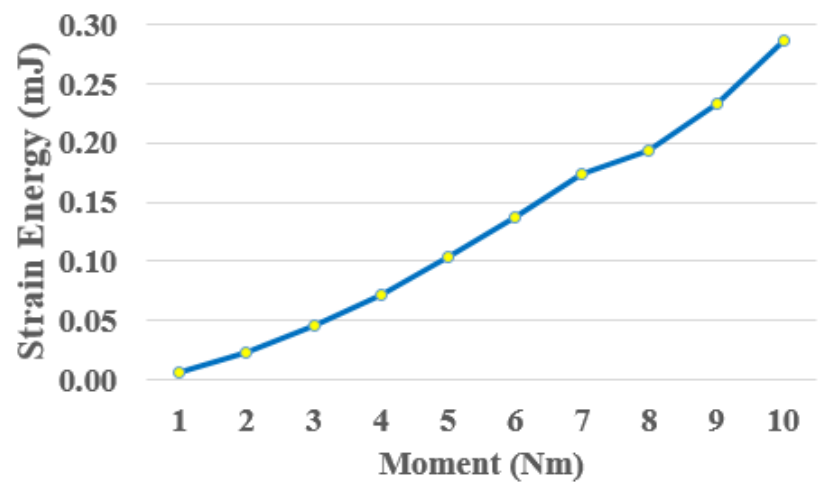

Figure 11: Correlation between the moment and strain energy

Finally, the performance of the dynamic splint based on pulley rotation was defined by the following parameters, as given in Table 2.

Table 2: The locking system of dynamic splint

\begin{tabular}{l|l|l}
\hline PARAMETERS & VALUE & UNIT \\
\hline Stress & 25.0786 & $\mathrm{MPa}$ \\
\hline Strain energy & 0.2856 & $\mathrm{~mJ}$ \\
\hline Deformation & 0.3684 & $\mathrm{~mm}$ \\
\hline Safety factor & 1.14 & \\
\hline
\end{tabular}




\section{CONCLUSION}

The dynamic splint based on pulley rotation was proposed as a rehabilitation device to earlier release the hand of muscle tone for the stroke sufferers. This paper aims to design and analyze the model to find out the durability before manufacturing and applying it to the patient. The pulley part of the dynamic splint was designed with nine holes for achieving an easy way to lock. The shear stress of pulley is $0.026 \mathrm{~N} / \mathrm{mm}^{2}$.

The deformation, stress, and strain energy of the locking system section were analyzed by FEA. The results of deformation distribution in the locking system area were in the range 0.1 to $0.15 \mathrm{~mm}$ by the color parameter. On the other hand, the maximum von misses stress was approximately $25.0786 \mathrm{MPa}$ which located at the tip of the locker. The locker part is vulnerable parts to earlier fatigue material when the stress superior the tensile yield strength. However, it was still safe after computing the coefficient of safety factor about $\mathrm{n}=$ 1.14 with a moment $10 \mathrm{Nm}$. The other results found that the highest strain energy was $0.2856 \mathrm{~mJ}$ at the center of the locker. Furthermore, the stress and strain with input moments were in a good linear profile.

Future investigation will be fabricated of the prototype by using a 3D printer. The experiments will be carried out to the subjects after recruiting and they will be evaluated by therapists using the assessment theory of occupational therapy for upper limb extremity.

\section{ACKNOWLEDGMENTS}

This research is funded by the Ministry of Science and Technology of the Republic of China under Contract Number MOST 105-2221-E-151-016.

\section{REFERENCES}

[1] SAW, J. "Carotid artery stenting for stroke prevention", Canadian Journal of Cardiology, 30 (1), 22-34, Jan. 2014.

[2] W. G. MEMBERS, A. S. GO, D. MOZAFFARIAN, V. L. ROGER, E. J. BENJAMIN, J. D. BERRY, et al., "Heart disease and stroke statistics-2014 update: a report from the American Heart Association", circulation, vol. 129, pp. 28, Jan. 2014.

[3] HSIEH, F. I., CHIOU, H. Y., "Stroke: morbidity, risk factors, and care in Taiwan", Journal of Stroke, vol. 16(2), pp. 59, May. 2014.

[4] S. L. FRITZ, K. E. LIGHT, T. S. PATTERSON, A. L. BEHRMAN, S. B. DAVIS, "Active finger extension predicts outcomes after constraint-induced movement therapy for individuals with hemiparesis after stroke", Stroke, vol. 36, pp. 1172-1177, Jun. 2005.

[5] Y. X. SHI, J. H. TIAN, K. H. YANG, Y. ZHAO, "Modified Constraint-Induced Movement Therapy Versus Traditional Rehabilitation in Patients with Upper-Extremity Dysfunction After Stroke: A Systematic Review and Meta-Analysis", Archives of Physical Medicine and Rehabilitation, vol. 92, pp. 972982, Jun. 2011.

[6] C. H. LEE, Y. H. CHIU, H. Y. KAO, I. T. CHEN, I. N. LEE, W. H. HO, et al., "A Body-Sensed Motor Assessment System for Stroke Upper-Limb Rehabilitation: A Preliminary Study", In: 2013 IEEE International Conference on Systems, Man, and Cybernetics, pp. 3819-3824, Manchester, UK, Oct. 2013.

[7] WOLFE, C. D. A., STEVENS, A., Health Care Needs Assessment: The Epidemiologically Based Needs Assessment Reviews, London, CRC Press, 2018.

[8] HUSSAIN, I., SALVIETTI, G., MELI, L., PACCHIEROTTI, C., CIONCOLONI, D., ROSSI, S., PRATTICHIZZO, D, "Using the robotic sixth finger and vibrotactile feedback for grasp compensation in chronic stroke patients", In: 2015 IEEE International Conference on Rehabilitation Robotics (ICORR), pp. 67-72, Singapore, Aug. 2015.

[9] N. A. LANNIN, A. CUSICK, A. MCCLUSKEY, R. D. HERBERT, "Effects of splinting on wrist contracture after stroke", Stroke, vol. 38, pp. 111-116, Jan. 2007.

[10] H. K. YAP, N. KAMALDIN, J. H. LIM, F. NASRALLAH, J. C. GOH, C.-H. YEOW, "A magnetic resonance compatible soft wearable robotic glove for hand rehabilitation and brain imaging", IEEE Transactions on Neural Systems and Rehabilitation Engineering, vol. 25(6), pp. 782-793, Aug. 2016.

[11] B. WANG, A. MCDAID, M. BIGLARI-ABHARI, K. C. AW, "Design and development of a glove for post-stroke hand rehabilitation", In: 2017 IEEE International Conference on Advanced Intelligent Mechatronics (AIM), pp. 1047-1051, Munich, Germany, Jul. 2017.

[12] H. K. YAP, P. M. KHIN, T. H. KOH, Y. SUN, X. LIANG, J. H. LIM, et al., "A Fully Fabric-Based Bidirectional Soft Robotic Glove for Assistance and Rehabilitation of Hand Impaired Patients", IEEE Robotics and Automation Letters, vol. 2, pp. 1383-1390, Feb. 2017.

[13] H.-M. KIM, G.-S. KIM, "Development of a finger-rehabilitation robot for fingers' flexibility rehabilitation exercise", International Journal of Precision Engineering and Manufacturing, vol. 14, pp. 535-541, Apr. 2013. 
[14] D. LEONARDIS, M. BARSOTTI, C. LOCONSOLE, M. SOLAZZI, M. TRONCOSSI, C. MAZZOTTI, et al., "An EMG-controlled robotic hand exoskeleton for bilateral rehabilitation", IEEE Transactions on Haptics, vol. 8, pp. 140-151, Mar. 2015.

[15] H. LI, L. CHENG, "Preliminary study on the design and control of a pneumatically-actuated hand rehabilitation device", In: 2017 32nd Youth Academic Annual Conference of Chinese Association of Automation (YAC), pp. 860-865, Hefei, China, May. 2017.

[16] H. K. YAP, F. SEBASTIAN, C. WIEDEMAN, C.-H. YEOW, "Design and characterization of low-cost fabric-based flat pneumatic actuators for soft assistive glove application", In: 2017 International Conference on Rehabilitation Robotics (ICORR), pp. 1465-1470, London, UK, Jul. 2017.

[17] K. SERBEST, S. ATEŞ, A. H. STIENEN, "Design of an exercise glove for hand rehabilitation using spring mechanism", In: 2016 20th National Biomedical Engineering Meeting (BIYOMUT), pp. 1-5, Izmir, Turkey, Nov. 2016.

[18] S. BIGGAR, W. YAO, "Design and evaluation of a soft and wearable robotic glove for hand rehabilitation", IEEE Transactions on Neural Systems and Rehabilitation Engineering, vol. 24, pp. 1071-1080, Jan. 2016.

[19] M. ALIMANOVA, S. BORAMBAYEVA, D. KOZHAMZHAROVA, N. KURMANGAIYEVA, D. OSPANOVA, G. TYULEPBERDINOVA, et al., "Gamification of Hand Rehabilitation Process Using Virtual Reality Tools: Using Leap Motion for Hand Rehabilitation”, In: 2017 First IEEE International Conference on Robotic Computing (IRC), pp. 336-339, Taichung, Taiwan, Apr. 2017.

[20] C.-L. HSU, S.-H. LU, T.-W. LIN, "Design and evaluation of stroke rehabilitation games based on clinical knowledge with virtual reality technology", In: 2017 IEEE Great Lakes Biomedical Conference (GLBC), pp. 1-1, Milwaukee, WI, USA, Apr. 2017.

[21] X. HUANG, F. NAGHDY, G. NAGHDY, H. DU, "Clinical effectiveness of combined virtual reality and robot assisted fine hand motion rehabilitation in subacute stroke patients", In: 2017 International Conference on Rehabilitation Robotics (ICORR), pp. 511-515, London, UK, Jul. 2017.

[22] X. HUANG, F. NAGHDY, G. NAGHDY, H. DU, C. TODD, "The Combined Effects of Adaptive Control and Virtual Reality on Robot-Assisted Fine Hand Motion Rehabilitation in Chronic Stroke Patients: A Case Study", Journal of Stroke and Cerebrovascular Diseases, vol. 27(1), pp. 221-228, Jan. 2017.

[23] J. CHEN, D. NICHOLS, E. B. BROKAW, P. S. LUM, "Home-based Therapy after Stroke Using the Hand Spring Operated Movement Enhancer (HandSOME)", IEEE Transactions on Neural Systems and Rehabilitation Engineering, vol. 25(12), pp. 2305-2312, Apr. 2017.

[24] C. L. JONES, F. WANG, R. MORRISON, N. SARKAR, D. G. KAMPER, "Design and development of the cable actuated finger exoskeleton for hand rehabilitation following stroke", IEEE/ASME Transactions on Mechatronics, vol. 19(1), pp. 131-140, Nov. 2014.

[25] H. C. FISCHER, K. M. TRIANDAFILOU, K. O. THIELBAR, J. M. OCHOA, E. D. LAZZARO, K. A. PACHOLSKI, et al., "Use of a portable assistive glove to facilitate rehabilitation in stroke survivors with severe hand impairment", IEEE Transactions on Neural Systems and Rehabilitation Engineering, vol. 24(3), pp. 344-351, Dec. 2015.

[26] I.C. BAEK, G.H. JEON, C.-H. YU, K. KIM, S. H. KIM, "Wireless Active Finger Rehabilitation Method Using Three-Axis Electromagnetic Manipulation", IEEE Transactions on Magnetics, vol. 53(11), pp. 15, Apr. 2017.

[27] M. GermanotTA, V. GOWER, D. PAPAdOPOUlou, A. CRUCIANI, C. PECCHIOLI, R. MOSCA, A MONTESANO, et al, "Reliability, validity and discriminant ability of a robotic device for finger training in patients with subacute stroke", Journal of Neuro Engineering and Rehabilitation, vol. 17(1), pp. 1-10, Des. 2020.

[28] P. G. LINDBERG, J. GÄVERTH, M. ISLAM, A. FAGERGREN, J. BORG, H. FORSSBERG, "Validation of a new biomechanical model to measure muscle tone in spastic muscles", Neurorehabilitation and neural repair, vol. 25(7), pp. 617-625, Sep. 2011.

[29] R. ZOU, Y. XIA, S. LIU, P. HU, W. HOU, Q. HU, et al., "Isotropic and anisotropic elasticity and yielding of 3D printed material", Composites Part B: Engineering, vol. 99, pp. 506-513, Aug. 2016.

[30] B. TYMRAK, M. KREIGER, J. M. PEARCE, "Mechanical properties of components fabricated with open-source 3-D printers under realistic environmental conditions", Materials \& Design, vol. 58, pp. 242-246, Jun. 2014.

[31] S. DUL, L. FAMBRI, A. PEGORETTI, "Filaments Production and Fused Deposition Modelling of ABS/Carbon Nanotubes Composites", Nanomaterials, vol. 8, pp. 49, Jan. 2018. 
[32] SETIYAWAN, K., SUGIANTORO, B., SUTISNA, U., RUSNALDHY, R., \& WIDYANTO, S. A. "Analysis of Physical and Mechanical Properties of Multiwalled Carbon Nano Tubes (MW-CNTs) Reinforced Mineral Composites as an Environmentally Friendly Machine Structure", Rekayasa Mesin, vol 10 (3), pp. 339-352, Jan. 2020. 